\title{
Research on Standardization of Examination Training for Graduate Entrance Examinations Under the Normalization of Epidemic Prevention and Control
}

\author{
Ke Deng ${ }^{1}$ and Kun Zhang ${ }^{2, *}$ \\ ${ }^{1}$ School of Continuing Education, Guangxi University of Science and Technology, Liuzhou Guangxi, 545006, China \\ ${ }^{2}$ Graduate School, Guangxi University of Science and Technology, Liuzhou, Guangxi 545006, China \\ * Corresponding author. Email: 1169360463@qq.com
}

\begin{abstract}
The normalization of epidemic prevention and control has put forward new requirements for the work of standard setting of postgraduate entrance examination and the training work of test centers. How to ensure the quality and efficiency of the training work is a new challenge for the majority of test staff, especially trainers. As an effective way to improve the quality of examination training, standardized examination training provides a possibility for the standardization and scientization of examination management. Through the in-depth exploration of the model examination site, the paper has formed a complete and effective standardized examination training video materials, which are implemented in the district. It has made it possible to carry out the examination training accurately, effectively and with high quality during the epidemic period.
\end{abstract}

Keywords: postgraduate, the test organization, training, standard

\section{INTRODUCTION}

At present, the transmission of COVID-19 in China has been basically blocked. Although sporadic cases have appeared in some areas, the epidemic has been brought under control. However, the momentum of COVID-19 is still strong abroad, and some countries have repeatedly seen clusters of COVID-19. With the increasing pressure of overseas import, the policy of "preventing import from abroad and preventing rebound in China" has become a normal measure for epidemic prevention and control. Minimize the aggregation activity is a necessary part of the prevention and control, therefore, all walks of life are constantly formulating new work standards to cope with the impact of this epidemic. As a special job, the postgraduate entrance examination is inevitably affected, how to set new work standards and what kind of standards should be considered by examination staff and administrators at present.

The sudden outbreak of COVID-19 has made the country and society aware that high-level talents serving the national strategy and social livelihood are still in short supply. Therefore, the expansion of graduate student enrollment has become an important practical measure for the country and the government to deal with the impact of THE COVID-19 epidemic and stabilize employment. With the introduction of the policy of further expanding the enrollment scale of master's degrees, the number of master's degree applicants in China is increasing, which poses a lot of challenges to the development of our postgraduate entrance examination. The current traditional management mode of examination has been unable to accurately solve the problems caused by the low quality of examination training due to the numerous examination sites, different scales and different qualities of examination staff. As an important part of examination management, examination training is an effective way to achieve zero error in the examination work by promoting its scientific, standardized and standardized development. Therefore, standardized examination training as pre-job training management scientific, standardized choice.

The presence of the epidemic is not only a challenge to our current examination training mode, but also a great opportunity for our work to be scientific and standardized. Then, how to achieve the smooth completion of science examination training work without any mistakes in large crowds? With the support of Guangxi Zhuang Autonomous Region Admissions Examination Institute, in-depth investigation of the current examination training mode in the entrance examination points of colleges and universities in the region. After careful analysis and comparison, based on the zero-error examination training mode of X School's admission examination site over the years, the field simulation technology is adopted to realize the accurate restoration of the whole examination work flow. According to the problems existing in the examination training at the current entrance examination points of colleges and universities in the region, an examination training video suitable for promotion in the whole region was produced. In order to establish a complete and practical standardized 
examination training system in our region, so as to promote the standardized and scientific process of examination training in our region

\section{SITUATION}

\subsection{The Examination staff management level is not high}

With the continuous expansion of examination scale, the tedious degree and workload of examination work have been improved. Especially, many factors, such as the change of personnel training mode, put forward higher requirements for the work ability of examination management personnel. However, through the analysis of the organization process of previous examinations, it is found that the existing examination business training focuses on the invigilators, but pays less attention to inspectors and examination managers[1]. However, with the change of the situation, the examination management system is updated too fast. Coupled with the expansion of the examination scale, the experienced invigilators in examination site can no longer meet the invigilation work of postgraduate entrance examination.

In this case, the examination management personnel are increasingly struggling with the management work such as examination invigilation training. Therefore, it has become the first choice for each examination site to temporarily fill the invigilation work by transferring personnel from administrative posts. The advantage of this method is that it can better convey the special requirements of the exam and meet the smooth progress of the exam to a certain extent . But the invigilators with too complex composition and the administrators with uneven working ability will inevitably lead to all kinds of mistakes and errors.

\subsection{The examination standards are inconsistent}

In the past examination organization process, according to the different size of the site and staffing, the examination management personnel of each examination site made a lot of operation procedures suitable for this examination site, but these procedures will always appear various problems in the actual operation, it has brought great influence to the examination management work. The main impacts are as follows:

First, the examination site staff is mobile: Test centers lack a complete and stable examination management team. The examination staff mainly refer to the examiners, deputy examiners, examination leaders, invigilators, security, medical care, logistics, etc. However, some test centers often have uncertain posts, resulting in low skill level of examination staff and inadequate handling of urgent matters.
Second, the specific division of labor is not clear: The division of specific examination work accusations in the examination site is inconsistent, and most staff members cannot clearly understand their job responsibilities and scope of work. Therefore, the examination management personnel have some obstacles in the work coordination and cooperation.

Third, there are great differences in examination standards:According to their own needs, the examination management personnel have formulated or perfected the examination work flow which accords with the actual situation of the examination center, which leads to the difference between high and low standards in examination work verification. For a specific examination work (such as examination training), some examination site will put forward the work requirements of this test site according to the actual situation and carry out assessment, while other examination sites will not increase the assessment standards to meet the requirements of "safety examination".

\subsection{The information feedback mechanism is not perfect}

In real life, the exchange of information between individuals in an organization and the outside is not a simple material transfer, and the success of this process depends to a certain extent on the subject's perception of information. On formal occasions, especially in special places such as examination work, the feedback among examiners will be influenced by the external environment. On the one hand, as the organizer and coordinator of the on-site examination work, the examination management personnel's authority given by their work and unequal information would bring certain pressure to invigilators. On the other hand, examiners and invigilators are two very important links in the feedback process, their personality quality and interpersonal perception will lead to the deviation of information feedback with too much individual subjective color.

Especially, the information in a single form (such as plain text) circulated during the examination time is more abstract than that of multimedia information, If the examiners have a certain deviation in understanding the same information due to their differences in personal qualities and ways of thinking, they will be transmitted to invigilators through the existing single feedback mechanism, so that the information distortion will continue to expand, resulting in operational errors and even violations 


\section{STANDARDIZED VIDEO EXAMINATION TRAINING}

\subsection{The postgraduate entrance examination system has been continuously improved.}

From the early 1980 s to the beginning of the 21 st century, China's postgraduate entrance examination system gradually transited from the early exploration stage to the mid-term construction stage[2]. During this period, the entrance examination subjects for full-time postgraduates were basically set at five subjects, and it was proved that the setting of these examination subjects was scientific and reasonable in practice. It has played a positive role in selecting innovative high-tech talents[3]. Therefore, since 2003, according to the first-level subjects, the Ministry of Education has changed the initial examination subjects from five to four, and put the specialized courses in the re-examination stage. In 2007, the Ministry of Education reformed the preliminary examination subjects according to the principle of "overall planning, classified guidance, steady advancement and gradual improvement[4].

These reforms have rationally distributed political theory, foreign languages, basic courses, professional basic courses and professional courses in the initial examination and re-examination, and the initial examination subjects have gradually developed in the direction of unified proposition by the state. On the one hand, it can improve the efficiency of talent selection, and at the same time, the country can master the selection criteria of talent.

\subsection{Benchmark examination site has been adopted as the blueprint for video training}

As a prefecture-level city, Liuzhou is an important central city approved by the State Council. Because it is located in the northeast of central Guangxi, connecting southwest with central south, east China and south China, Liuzhou is known as the "commercial port in central Guangxi". As the largest industrial base in Guangxi, Liuzhou is the only city in China that has four major automobile group production bases at the same time. Its unique geographical location and administrative region have been paid attention by the state and the district government.

Before 2018, Liuzhou was also the earliest test location in central Guangxi and the only test location in the region for a long time. The unique geographical location makes the exam location of X'school more unique than other exam locations in the region. The main performances are as follows:

First of all, the number of candidates and the types of test subjects are always in the top ranks in the entire region; Second, the intensity of the examination work and the high risk are relatively high among the examination site in the region. Third, the examination staff has experienced many changes in the examination system and accumulated rich experience. Examination staff is highly specialized and relatively stable. Fourth, the training is scientific and standardized. A set of relatively perfect examination training methods has been formed, from issuing written training materials to self-study examination work norms before the examination, to focusing on training before the examination, and then to focus on training examination staff in different positions in batches according to the division of examination work. Fifth, from 2006 to 2019, there were no obvious mistakes in the examination work, and the performance was at the forefront of the same examination site in the whole region.

\subsection{The video production technology is mature}

The development of modern science and technology accelerates the development of standardized examination rooms, from examination training to examination room inspection and examination room safety, which provides a solid guarantee for examination safety and fairness. However, after investigation, standardized examination training has not been realized in each examination site area, thus inhibiting the due efficiency of standardized examination rooms. Therefore, the combination of examination training and current media technology to further promote safety examination and fair examination is what we should pay attention to at present. Up to now, our team has mature experience in video production, and has produced more than ten videos before and after, which has attracted wide attention.

\section{CONCLUSION}

The completion of examination training directly affects the smooth progress of the examination. At present, affected by the epidemic situation, it is still necessary to avoid mass gathering. It is the first choice among many training methods to complete invigilation training through video training. On the one hand, video training further promotes the standardization process of examination work, and provides guarantee for the high-quality completion of examination work. On the other hand, it reduces expenses for postgraduate entrance examination. Video training can reduce the positions and costs of relevant trainers.

\section{REFERENCES}

[1] Jinhua Yin and Yanfang Zhu. research on new ideas of college examination work under the condition of standardized examination room [J]. science and education literature exchange (next issue), 2018(03): pp. $139-140$

[2] YingyuYu and Weitao Gao. Research on the Reform of Postgraduate Entrance Examination System in China [J]. Heilongjiang Higher Education Research, 2010(10): pp.102-104. 
[3] Jingjing Ji. Analysis of China's postgraduate entrance examination system reform [J]. Science and Technology Economic Guide, 2016(30): pp.185-186.
[4] Hongchuan Luo. Risk assessment of postgraduate entrance examination $[\mathrm{J}]$. International Public Relations, 2020(02): p.213. 